\title{
EFFECT OF HAFNIUM AND ZIRCONIUM TO GLASS FORMING ABILITY, THERMAL STABILITY, PLASTICITY DEFORMATION AND CRYSTALLIZATION OF Ni-FREE PENTABASIC Ti-BASED BULK METALLIC GLASSES
}

\begin{abstract}
The newly designed Ti-based bulk metallic glass (BMG) in which case of fracture behavior was observed 1990MPa to compressive strength with a wide plastic deformation around $7 \%$ after process of elastic deformation. This phenomenon can be compared with those of Ti-based alloys and other Ti-based BMGs and indicates high potential to be applied in use. It was evaluated the Ti-based BMG for thermal stability that the reduced glass parameters, $\Delta T_{x}, T_{r g}$ and $\gamma$, are $79 \mathrm{~K}, 0.50$ and 0.38 , respectively. In addition, it reveals high activation energies for crystallization in which are estimated to $E_{x 1}=291.77 \pm 9.71 \mathrm{~kJ} / \mathrm{mol}, E_{x 2}=588.77$ $\pm 28.88 \mathrm{~kJ} / \mathrm{mol}$ and $E_{\mathrm{x} 3}=330.26 \pm 3.61 \mathrm{~kJ} / \mathrm{mol}$ on kissinger plotting in this study.

Keywords: Ti-based alloy, metallic glass, Ti fiber, glass formability, plastic deformation
\end{abstract}

\section{Introduction}

Titanium and its alloys have been developed rapidly due to their own unique properties, hence these materials evolved into commercialization for multi-purpose materials [1]. From the point of view in effective usage extension of these materials, Ti-based amorphous alloys are one of the optimized materials because of their own extraordinary specific strength, superior corrosion resistance as well as flow-viscous plastic workability and consolidation at supercooled liquid region (SLR). The expression of SLR and bulk forming ability (BFA) in amorphous state contributed to increase scientific interest and has a high potential of industrial application [2]. Recently, Ti-based amorphous alloys and Ti-based BMGs have been attempted to apply as bio-medical application by $\mathrm{Ni}$-free Ti-based metallic glasses [3-8]. According to these results, Ni-, Al- and Be-free type Tibased BMGs indicate design criteria without these elements, increase of mechanical strength, decrease of elastic modulus as well as enhancement of corrosion resistance by amorphization and additional element effect. Therefore, These Ti-based BMGs reveal high biocompatibility in vitro and vivo test. Unfortunately, the expression of poor plastic deformation has limited availability of Ti-based BMGs without $\mathrm{Ni}, \mathrm{Al}$ and $\mathrm{Be}$ as structural materials even with extraordinary properties. This viewpoint, "complete thermodynamic equilibrium in a system is reached only when mechanical equilibrium, thermal equilibrium, and chemical equilibrium are simultaneously achieved" [9], is considered to be analysed metallic glasses with metastable state into its heterogeneity element stability of glass forming ability. In this study, analogous compositions, $\mathrm{Ti}_{45} \mathrm{Hf}_{10} \mathrm{Pd}_{10} \mathrm{Cu}_{30} \mathrm{Sn}_{5}$ (at. \%) and $\mathrm{Ti}_{45} \mathrm{Zr}_{10} \mathrm{Pd}_{10} \mathrm{Cu}_{30} \mathrm{Sn}_{5}$ (at. \%) in Ti-Zr-Pd-Cu-Sn alloy system [10], were studied for understand mechanical property change and phase formation in critical BFA and initial state crystallization. Unfortunately, no details for understanding these phenomenon has been reported. This study provides a comprehensive consideration in alloy design of Ti-based metallic glass through understanding of phase formation from liquid phase for increasing mechanical properties as biomaterials.

\section{Experimental methods}

Master alloys of $\mathrm{Ti}_{45} \mathrm{Hf}_{10} \mathrm{Pd}_{10} \mathrm{Cu}_{30} \mathrm{Sn}_{5}$ (at. \%) and $\mathrm{Ti}_{45} \mathrm{Zr}_{10}$ $\mathrm{Pd}_{10} \mathrm{Cu}_{30} \mathrm{Sn}_{5}$ (at. \%) as reference alloys were prepared by arc melting the mixture of purity metals, i.e. Ti (99.9999 wt. \% min.), Hf (99.999 wt. \%min.), Zr (99.99 wt. \% min.), Pd (99.9 wt. \% min.), $\mathrm{Cu}(99.9999$ wt. \% min.) and $\mathrm{Sn}(99.99$ wt. \% min.) in an argon atmosphere. These alloys were used to make melt-spun of $20 \mu \mathrm{m}$ in thickness and $1 \mathrm{~mm}$ in width by a single roll melt spinning technique. These cylindrical rod specimens with nominal compositionswere prepared byinjection and suction casting technique formeach molten alloy into copper moldwhich process has make to re-melting above the master ingots by high frequency radiation in an inert gas condition. The structural properties of as-casted samples were examined by X-ray diffraction (XRD: D8 BRUKER, Germany) using $\mathrm{Cu}$ K $\alpha$ radiation at $40 \mathrm{kv}, 40 \mathrm{~mA}$.

\footnotetext{
* MATERIAL ANALYSIS LABORATORY, DAE-IL CORPORATION, 8, BONGGYENONGGONG-GIL, DUDONG-MYEON, ULJU-GUN, ULSAN 44914, REPUBLIC OF KOREA ** DEPARTMENT OF MATERIALS SCIENCE AND ENGINEERING, PUSAN NATIONAL UNIVERSITY, BUSAN, REPUBLIC OF KOREA

*** SOCIAL ENTERPRISE, PUSAN NATIONAL UNIVERSITY, BUSAN, REPUBLIC OF KOREA 
Uniaxial compressive tests were performed at room temperature by an Instron type machine (SHIMADZU: Autograph AG-X $50 \mathrm{kN}$, Japan) with a strain gauge attached to the samples with strain rate $(\dot{\varepsilon})$ for $5 \times 10^{-4} \cdot \mathrm{s}^{-1}$. Specimens in compressive test have the gauge dimensions with $2.5 \times 2.5 \times 5.0 \mathrm{~mm}$. The thermal stability associated with crystallization temperature $\left(T_{x}\right)$, glasstransition temperature $\left(T_{g}\right)$ and the supercooled liquid region (SLR: $\Delta T_{x}=T_{x}-T_{g}$ ) was examined by differential scanning calorimetry (DSC: ParkinElmer, 8500 , USA) at a heating rate of from $10 \mathrm{~K} / \mathrm{min}, 20 \mathrm{~K} / \mathrm{min}, 40 \mathrm{~K} / \mathrm{min}, 80 \mathrm{~K} / \mathrm{min}$ and $100 \mathrm{~K} /$ min. Differential thermal analysis (DTA: QTA600, USA) also was performed to measure the melting $\left(T_{m}\right)$ and liquidus $\left(T_{\ell}\right)$ temperatures of these alloys with a heating rate of $0.67 \mathrm{~K} / \mathrm{s}$. Microstructure and fracture surface were observed with a field emission scanning electron microscopy (SEM: FE-SEM, TESCAN MIRA 3, Czech Republic). Qualitative and quantitative analysis of microstructure were carried out by energy-dispersive $\mathrm{x}$-ray spectroscopy (EDS) analysis systems and electron back scatter diffraction (EBSD) method.

\section{Results and discussion}

Fig. 1a exhibits thermal behaviour of melt-spun specimens in which has SLR and crystallization with three exothermic events. This phenomenon indicates amorphization of these melt-spun specimens by rapid quenching process. Especially, Hf containing Ti-based (HT) melt-spun has a wide SLR in region I and temperature interval difference between $1^{\text {st }}$ crystallization region and $2^{\text {nd }}$ crystallization region in region II than those of $\mathrm{Zr}$ containing Ti-based (ZT) melt-spun. Fig. 1b shows bulk forming ability (BFA) of HT alloy. Critical formability size with an amorphous phase by injection casting technique was identified as $3.0 \mathrm{~mm}$ in diameter. Amorphous phase (as shown in XRD pattern for $2.5 \mathrm{~mm}$ specimen) of I-casted HT BMG is completely stable state before and after compressive test. Fig. 1c exhibits mechanical properties by compressive test at room temperature. Strain-stress curve of the I-casted HT BMG clearly exhibits a higher compressive strength for $1990 \mathrm{MPa}$, lower elastic modulus for $94 \mathrm{GPa}$ and plastic deformation for $7 \%$ in longitudinal
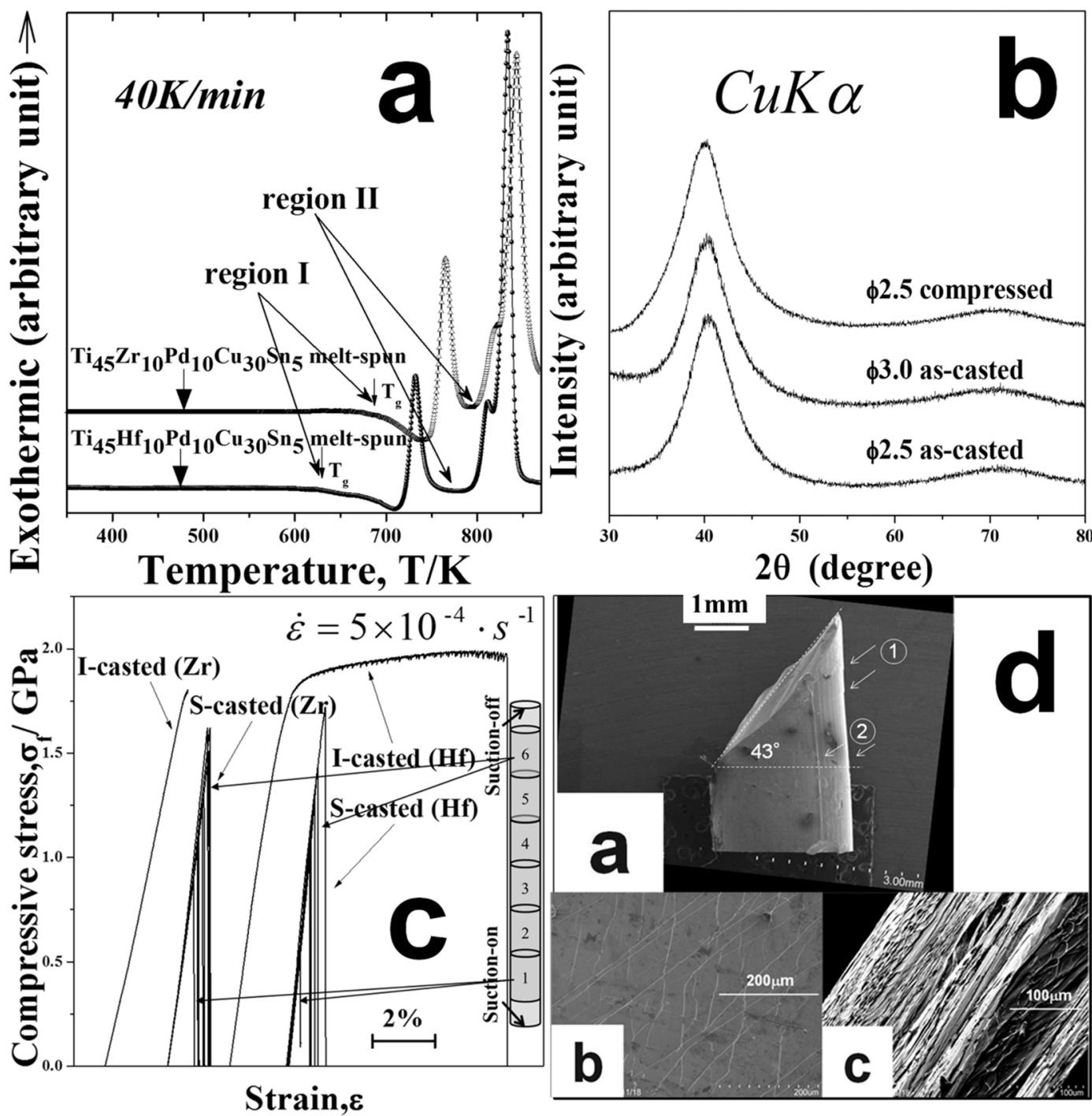

Fig. 1. DSC traces of the melt-spun HT and ZT alloys(a), XRD patterns of injection-casted (I-casted) HT for compressive test and critical BFA (b), and compressive strain-stress curve of (I-casted) and suction-cased (S-casted) specimens in $\mathrm{Ti}_{45} \mathrm{Hf}(\mathrm{Zr})_{10} \mathrm{Pd}_{10} \mathrm{Cu}_{30} \mathrm{Sn}_{5}$ alloys (c) and illustrative scanning electron microscopy images of out morphology (d-a), side view(d-b) and fracture surface(d-c) by compressive test at room temperature 
variation. These improved mechanical properties are compared with those of the I-casted ZT BMG and the S-casted HT and ZT alloys. Fig. 1b well explains that plastic deformation of I-casted HT BMG with BFA occurred in amorphous state, and there was no significant crystallization in tested specimen as shown in Fig. $1 \mathrm{~d}$ and keeping the symmetrical balance based on central axis for amorphous main broad peak in end stage of plastic deformation. Observed shear band propagation was well developed based on longitudinal direction for $43^{\circ}$ under a unidirectional stress in Fig. 1d (a) and Fig. 1d (a) (1). Outside surface and parting line in the tested specimen (as shown in Fig. 1d (a)(2)) show high crush resistance and barrelling phenomenon as regional deformation by plastic deformation. In addition, external surface of the tested specimen has multi-shear band formation in Fig. 1d (b). It was caused by abundance of homogeneously-distributed free volume in glass matrix. Fig. 1d (c) exhibits an inclined fracture surface with vein-like patterns, and indicates high rub resistance. Veinlike patterns caused flow viscosity behavior in molten traces by increasing regional temperature by friction. These phenomena have strong relationship between the plastic deformation occurred by activation of free volume, and the increased local flow viscosity before losing all flow viscosity.

Fig. 2 shows microstructures of the S-casted HT alloy and the S-casted ZT alloy in suction-on part. There are three kinds of the obvious decomposed intermetallic phases from these alloys in (Fig. 2a,d). In addition, (Fig. 2b,e), and (Fig. 2c,f) were observed for evaluation of the variation of microstructure according to existence of dark contrast phase in crystallization of these alloys. In case of the S-casted HT alloy, it was observed that partially developed ellipsoidal dark contrast phase as shown in Fig. 2b(1), grey contrast phases were consisted of narrow platetype as shown in Fig. 2b-2 and c1 and orchid flower shaped dendrite structures in Fig $2 b 3$ and $c(2$. And then, narrow plate-type with bright contrast as shown in Fig. $2 b(4$ and $c(3)$.
In case of the S-casted ZT alloy, partially developed ellipsoidal dark contrast phase as shown in Fig. 2e(1), two tone grey contrast of non-rectangular needle-shaped phases as shown in Fig. 2e(2) and $\mathrm{f}(1)$ and its inside phase in Fig. 2e(3) and f(2), and bright matrix phase in Fig. 2e(4) and $\mathrm{f}(3$ are observed.

EDS analysis of suction-on parts in Table 1 and XRD patterns of all suction parts in Fig. 3 clearly indicate relationship of crystallization between phase morphology and elementary composition, each phase formation as well as explain diffusion route of each element in each molten alloy under the cooling process. According to comprehensive review from EDS analysis and XRD patterns of the S-casted alloys, partially developed ellipsoidal dark contrast phases of the S-casted HT alloy in (Fig. 2a,d) is pure Ti phase, two type grey contrast phases are main matrix of HT alloy in Fig. 2b(2) and c(1) and $\mathrm{TiSn}\left(\mathrm{SnTi}_{3}\right)$ phase in Fig. $2 \mathrm{~b}(3$ and $\mathrm{c}(2$, respectively. Bright phases in Fig. 2b(4) and $\mathrm{c}(3)$ are composed of complex phases with $\operatorname{TiPd}\left(\mathrm{Pd}_{3} \mathrm{Ti}\right), \mathrm{TiCu}\left(\mathrm{CuTi}_{2}\right)$ and $\mathrm{CuHf}\left(\mathrm{CuHf}_{2}\right)$ in Fig. 3. Meanwhile, two type grey contrast phases in Fig. 2e(2) and f(1) and Fig. 2e(3) and $\mathrm{f} 2$ in the S-casted ZT alloy are seems to be composed $\mathrm{TiPd}\left(\mathrm{Pd}_{3} \mathrm{Ti}\right), \mathrm{TiCu}\left(\mathrm{CuTi}_{2}\right)$ and $\mathrm{CuZr}\left(\mathrm{CuZr}_{2}\right)$ and $\mathrm{TiSn}\left(\mathrm{SnTi}_{3}\right)$ phase, respectively. Bright phases in Fig. 2e(4) and f(3) are main matrix of ZT alloy. Overall, predicted diffusion route and decomposition based on reaction temperature by cooling process is a follows [11-13]; The molten HT alloy (L) $\rightarrow \mathrm{L}$ $+\left(\mathrm{SnTi}_{3}+\mathrm{L}(\mathrm{Cu}\right.$-rich $\left.)\right) \rightarrow \mathrm{L}+\left(\mathrm{Ti}+\mathrm{SnTi}_{3}+\mathrm{L}(\mathrm{Cu}-\right.$ rich $\left.)\right) \rightarrow \mathrm{L}+$ $\left(\mathrm{Ti}+\mathrm{SnTi}_{3}+\mathrm{Pd}_{3} \mathrm{Ti}+\mathrm{L}(\mathrm{Cu}-\right.$ rich $\left.)\right) \rightarrow \mathrm{L}+\left(\mathrm{Ti}+\mathrm{SnTi}_{3}+\mathrm{Pd}_{3} \mathrm{Ti}+\right.$ $\left(\mathrm{L}(\mathrm{Cu}-\right.$ rich $\left.\left.) \rightarrow \mathrm{CuHf}_{2}\right)\right) \rightarrow \mathrm{L}+\left(\mathrm{Ti}+\mathrm{SnTi}_{3}+\mathrm{Pd}_{3} \mathrm{Ti}+(\mathrm{L}(\mathrm{Cu}-\right.$ rich $)$ $\left.\left.\rightarrow \mathrm{CuHf}_{2}+\mathrm{Cu}_{51} \mathrm{Hf}_{14}\right)\right) \rightarrow \mathrm{L}+\left(\mathrm{Ti}+\mathrm{SnTi}_{3}+\mathrm{Pd}_{3} \mathrm{Ti}+(\mathrm{L}(\mathrm{Cu}-\right.$ rich $)$ $\left.\left.\rightarrow \mathrm{CuHf}_{2}+\mathrm{Cu}_{51} \mathrm{Hf}_{14}+\mathrm{CuTi}_{2}\right)\right) \rightarrow \mathrm{L}+\left(\mathrm{Ti}+\mathrm{SnTi}_{3}+\mathrm{Pd}_{3} \mathrm{Ti}+\right.$ $\left(\mathrm{L}(\mathrm{Cu}-\right.$ rich $\left.\left.) \rightarrow \mathrm{CuHf}_{2}+\mathrm{Cu}_{51} \mathrm{Hf}_{14}+\mathrm{CuTi}_{2}+\mathrm{Cu}_{10} \mathrm{Hf}_{7}\right)\right)$ and the molten ZT alloy $(\mathrm{L}) \rightarrow \mathrm{L}+\left(\mathrm{SnTi}_{3}+\mathrm{L}(\mathrm{Cu}-\right.$ rich $\left.)\right) \rightarrow \mathrm{L}+(\mathrm{Ti}+$ $\mathrm{SnTi}_{3}+\mathrm{L}(\mathrm{Cu}-$ rich $\left.)\right) \rightarrow \mathrm{L}+\left(\mathrm{Ti}+\mathrm{SnTi}_{3}+\mathrm{Pd}_{3} \mathrm{Ti}+\mathrm{L}(\mathrm{Cu}-\right.$ rich $\left.)\right) \rightarrow$ $\mathrm{L}+\left(\mathrm{Ti}+\mathrm{SnTi}_{3}+\mathrm{Pd}_{3} \mathrm{Ti}+\left(\mathrm{L}(\mathrm{Cu}-\right.\right.$ rich $\left.\left.) \rightarrow \mathrm{CuTi}_{2}\right)\right) \rightarrow \mathrm{L}+(\mathrm{Ti}+$

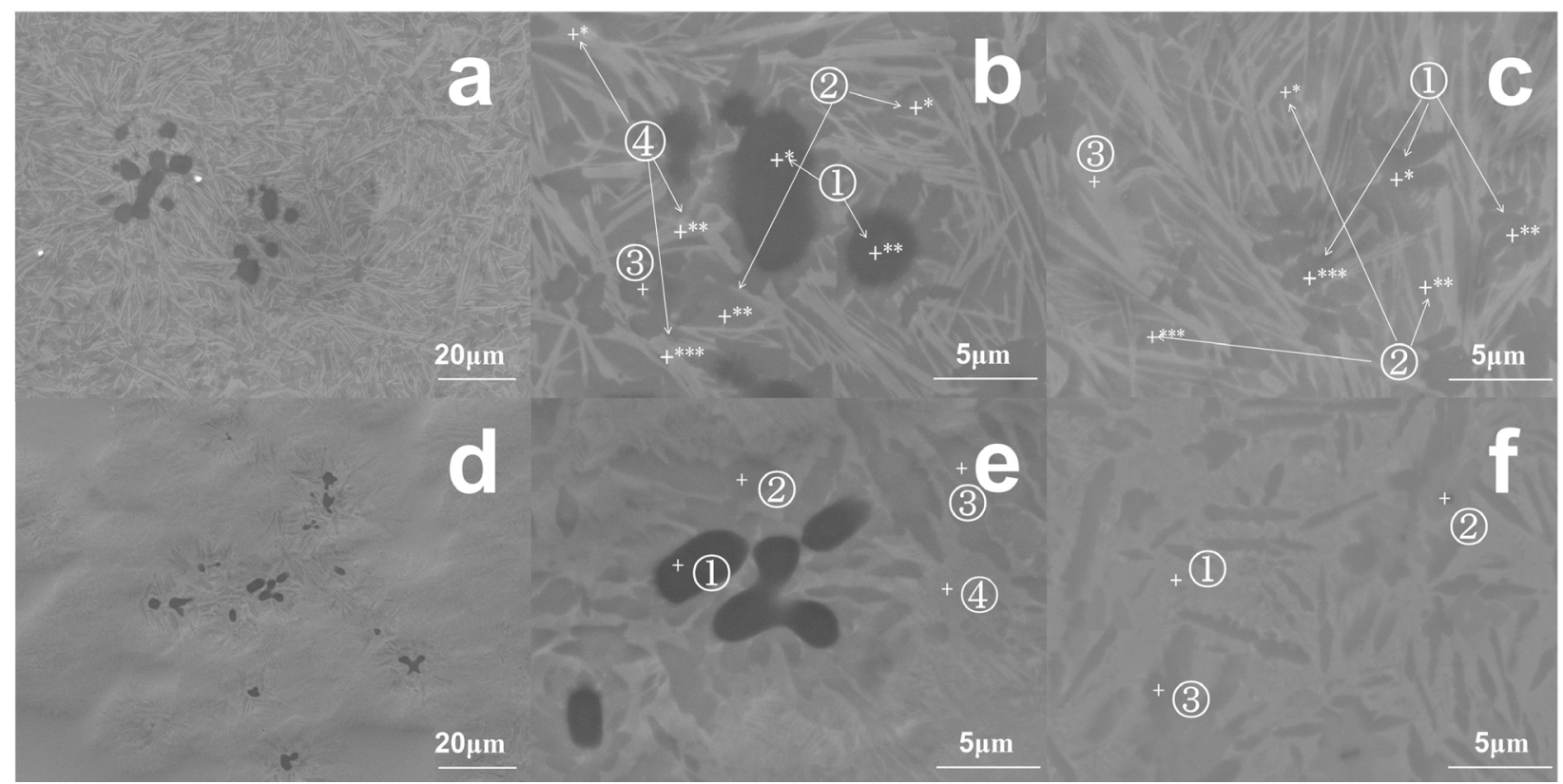

Fig. 2. Microstructure phases of S-casted HT alloy (a-c) and ZT alloy (d-f) in suction-on part as shown in Fig. 1c 
EDS analysis for phase chracteraztion of suction-casted Ti-based alloys in Fig. 2

\begin{tabular}{|c|c|c|c|c|c|c|c|c|c|c|c|c|c|c|}
\hline \multirow{2}{*}{ at. $\%$} & \multicolumn{4}{|c|}{ b } & \multicolumn{3}{|c|}{ C } & \multicolumn{4}{|c|}{ e } & \multicolumn{3}{|c|}{ f } \\
\hline & (1) & (2) & (3) & (4) & (1) & (2) & (3) & (1) & (2) & (3) & (4) & (1) & (2) & (3) \\
\hline$T i K$ & $\begin{array}{l}91.52^{*} \\
90.30^{* *}\end{array}$ & $\begin{array}{l}51.82^{*} \\
53.31^{* *}\end{array}$ & 70.46 & $\begin{array}{c}24.93^{*} \\
20.62^{* *} \\
22.35^{* * *}\end{array}$ & $\begin{array}{c}48.32^{*} \\
48.37^{* *} \\
50.86^{* * *}\end{array}$ & $\begin{array}{c}67.60^{*} \\
65.98^{* *} \\
72.31^{* * *}\end{array}$ & 24.21 & 94.46 & 51.74 & 66.86 & 35.67 & 55.53 & 75.03 & 41.28 \\
\hline $\begin{array}{c}H f L(b, c) \\
\operatorname{ZrL}(e, f)\end{array}$ & $\begin{array}{l}05.56^{*} \\
07.32^{* *}\end{array}$ & $\begin{array}{l}11.62^{*} \\
11.43^{* *}\end{array}$ & 04.02 & $\begin{array}{c}15.06^{*} \\
19.39^{* *} \\
15.22^{* * *}\end{array}$ & $\begin{array}{c}12.86^{*} \\
13.14^{* *} \\
11.78^{* * *}\end{array}$ & $\begin{array}{c}04.00^{*} \\
04.51^{* *} \\
04.08^{* * *}\end{array}$ & 14.85 & 02.90 & 07.96 & 04.84 & 13.01 & 06.21 & 04.16 & 10.11 \\
\hline$P d L$ & $\begin{array}{c}00.56^{*} \\
00.46^{*}\end{array}$ & $\begin{array}{c}09.64^{*} \\
09.03^{* *}\end{array}$ & 01.64 & $\begin{array}{c}16.97^{*} \\
14.59^{* *} \\
18.81^{* * *}\end{array}$ & $\begin{array}{c}09.92^{*} \\
09.31^{* *} \\
09.63^{* * *}\end{array}$ & $\begin{array}{c}01.99^{*} \\
02.79^{* *} \\
01.91^{* * *}\end{array}$ & 17.47 & 00.39 & 11.71 & 02.44 & 11.50 & 11.68 & 01.82 & 11.33 \\
\hline CuK & $\begin{array}{c}00.66^{*} \\
00.90^{* *}\end{array}$ & $\begin{array}{c}25.43^{*} \\
23.71^{* *}\end{array}$ & 03.30 & $\begin{array}{c}42.41^{*} \\
44.60^{* *} \\
43.25^{* * *}\end{array}$ & $\begin{array}{c}27.62^{*} \\
27.61^{* *} \\
26.34^{* * *}\end{array}$ & $\begin{array}{c}04.98^{*} \\
06.73^{* *} \\
03.18^{* * *}\end{array}$ & 42.68 & 01.24 & 26.03 & 04.64 & 34.22 & 23.73 & 03.36 & 31.78 \\
\hline$S n L$ & $\begin{array}{c}01.70^{*} \\
01.02^{* *}\end{array}$ & $\begin{array}{c}01.50^{*} \\
02.52^{* *}\end{array}$ & 20.58 & $\begin{array}{c}00.62^{*} \\
00.80^{* *} \\
00.37^{* * *}\end{array}$ & $\begin{array}{c}01.29^{*} \\
01.56^{* *} \\
01.40^{* * *}\end{array}$ & $\begin{array}{c}21.43^{*} \\
19.99^{* *} \\
18.52^{* * *}\end{array}$ & 00.78 & 01.01 & 02.58 & 21.21 & 05.60 & 02.85 & 15.63 & 05.49 \\
\hline
\end{tabular}

$\mathrm{SnTi}_{3}+\mathrm{Pd}_{3} \mathrm{Ti}+\left(\mathrm{L}(\mathrm{Cu}-\right.$ rich $\left.\left.) \rightarrow \mathrm{CuTi}_{2}+\mathrm{CuZr}_{2}\right)\right) \rightarrow \mathrm{L}+(\mathrm{Ti}+$ $\mathrm{SnTi}_{3}+\mathrm{Pd}_{3} \mathrm{Ti}+\left(\mathrm{L}(\mathrm{Cu}-\right.$ rich $\left.\left.) \rightarrow \mathrm{CuTi}_{2}+\mathrm{CuZr}_{2}+\mathrm{Cu}_{8} \mathrm{Zr}_{3}\right)\right) \rightarrow \mathrm{L}$ $+\left(\mathrm{Ti}+\mathrm{SnTi}_{3}+\mathrm{Pd}_{3} \mathrm{Ti}+\left(\mathrm{L}(\mathrm{Cu}-\mathrm{rich}) \rightarrow \mathrm{CuTi}_{2}+\mathrm{CuZr}_{2}+\mathrm{Cu}_{8} \mathrm{Zr}_{3}\right.\right.$ $\left.\left.+\mathrm{Cu}_{10} \mathrm{Zr}_{7}\right)\right) \rightarrow \mathrm{L}+\left(\mathrm{Ti}+\mathrm{SnTi}_{3}+\mathrm{Pd}_{3} \mathrm{Ti}+\left(\mathrm{L}(\mathrm{Cu}-\mathrm{rich}) \rightarrow \mathrm{CuTi}_{2}+\right.\right.$ $\left.\left.\mathrm{CuZr}_{2}+\mathrm{Cu}_{10} \mathrm{Zr}_{7}+\mathrm{Cu}_{8} \mathrm{Zr}_{3}+\mathrm{Cu}_{2} \mathrm{TiZr}\right)\right)$. XRD patterns of all parts of S-casted HT and ZT specimens exhibit sensitive crystallinity dependence of these alloys under cooling process. Degrees of crystallization of $\mathrm{SnTi}_{3}$ and Ti phase as stabilized phase at high temperature of the two alloys were clearly different in Fig. 3. $\mathrm{Pd}_{3}$ Ti phase, on the other hand, shows low crystal growth in both alloys, Especially, crystallinity of $\mathrm{CuZr}_{2}$ could reveal how increased high glass formability of $\mathrm{ZT}$ alloy than $\mathrm{CuHf}_{2}$ phase of HT alloy in metastable phases under the same cooling process.

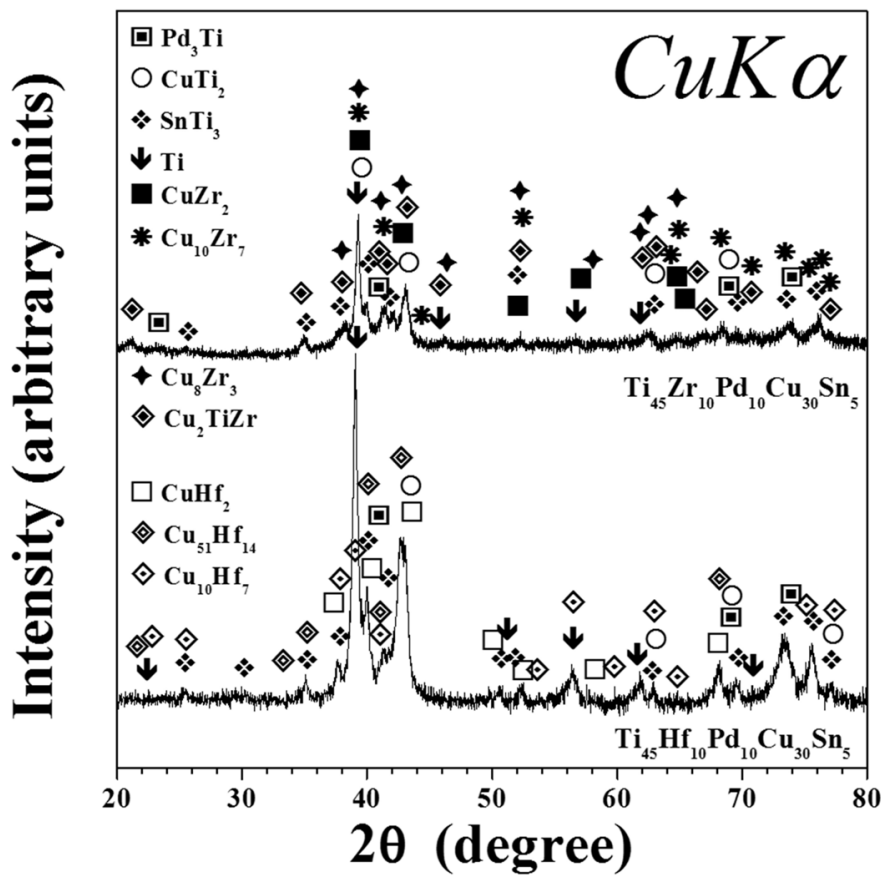

Fig. 3. XRD patterns of S-casted specimens for compressive test in this study
For value the validity of interpretation of solid phase crystallization behaviour, EBSD mapping of these S-casted specimens in suction-on part was carried out as shown in Fig. 4. Main crystallization of $\mathrm{Ti}_{3} \mathrm{Sn}$ phase, $\mathrm{CuTi}_{2}$ phase, $\mathrm{SnTi}_{3}$ phase, Ti phase, $\mathrm{CuHf}_{2}$ and $\mathrm{CuZr}_{2}$ phases dose good agree with identification of each phase in Fig. 2. Phase volume fraction of each $\mathrm{S}$ casted-HT and ZT alloy calculated $25.1 \%$ (confidence index (CI): 0.08 ) and $39.9 \%$ (CI: 0.06) for $\mathrm{Pd}_{3}$ Ti phase (cubic, $\mathrm{Fm} 3 \mathrm{~m}$ ), $2.6 \%(\mathrm{CI}: 0.06)$ and $8.4 \%(\mathrm{CI}: 0.10)$ for $\mathrm{CuTi}_{2}$ phase (tetragonal, I4/mmm), 7.5\%(CI:0.05) and 17. 9\%(CI:0.05) for $\mathrm{SnTi}_{3}$ phase (hexagonal, P63/mmc), 24, $2 \%(\mathrm{CI}: 0.33)$ and $20.5 \%(\mathrm{CI}: 0.21)$ for Ti phase(hexagonal, P63/mmc), $40.2 \%(\mathrm{CI}: 0.12)$ for $\mathrm{CuHf}_{2}$ phase (tetragonal, I4/mmm) and $13.3 \%(\mathrm{CI}: 0.05)$ for $\mathrm{CuZr}_{2}$ phase (tetragonal, I4/mmm).Each average CI of these alloys are 0.15 for S-casted HT alloy and 0.09 for S casted ZT alloy, respectively. Nano-crystallization of stable $\mathrm{Ti}_{3} \mathrm{Sn}$ phase and $\mathrm{CuTi}_{2}$ in initial crystallization at high temperature region shows the relationship between degree of supercooling of these alloys and potential of glass formability under same cooling rate in Fig. 4e,i [6]. In case of initial crystallization of these alloys, primary difference is synthesis of $\mathrm{Ti}_{3} \mathrm{Sn}$ phase in $\mathrm{ZT}$ alloy and $\mathrm{Pd}_{3}$ Ti phase in HT alloy. These main phases led to devitrification of glass matrix, and two different $\mathrm{Cu}$-rich phase matrix. Plastic deformation of HT BMG was traced back to deterrent effect of nucleation of $\mathrm{CuTi}_{2}, \mathrm{SnTi}_{3}$ and $\mathrm{Ti}$ phases which were going to growth brittle phases in these alloys.

Fig. 5 and Table 2 show etched surfaces of S-casted HT alloy in (a-c), and S-casted ZT alloy in (d-f) on suction-on part as shown in Fig. 1c. These crystalline phases in S-casted specimens indicate initial crystallization by a rapid cooling rate after finishing arc melting process. The synthesized phases exhibit cooling state in which degree of crystallinity and crystallization path during solidification. In addition, it is possible to predict what is vulnerable to corrosion on surface layer in these alloys. Observational selection effect for phases form etched traces in this study reflects crystal growth mechanism by solidification under the rapid cooling process in Fig. 2 and EDS results in Table 1. 


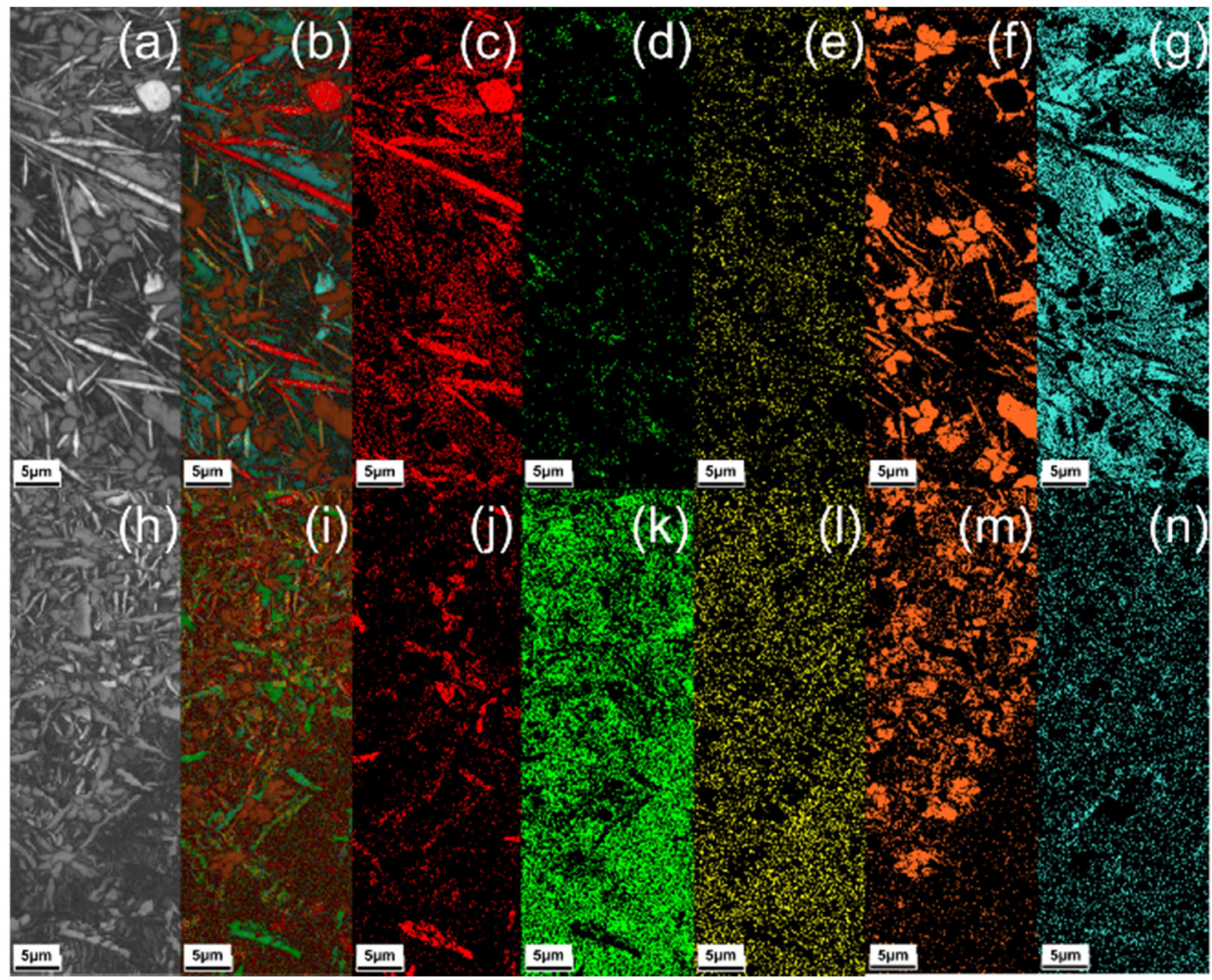

Fig. 4. EBSD phase mapping images of S-casted HT alloy (a-g) and S-casted ZT alloys (h-n) in initial forming phases of suction-on part as shown in Fig. 1c (EBSD images (a,h), total image mappings (b,i) Pd $\mathrm{Pd}_{3} \mathrm{Ti}\left(\right.$ red :(c,j)), $\mathrm{CuTi}_{2}$ (green:(d,k)), $\mathrm{SnTi}_{3}$ (yellow:(e,i)), Ti (orange:(f,m)), CuHf ${ }_{2}$ (cyan: (g)) and $\mathrm{CuZr}_{2}$ (cyan:(n)).

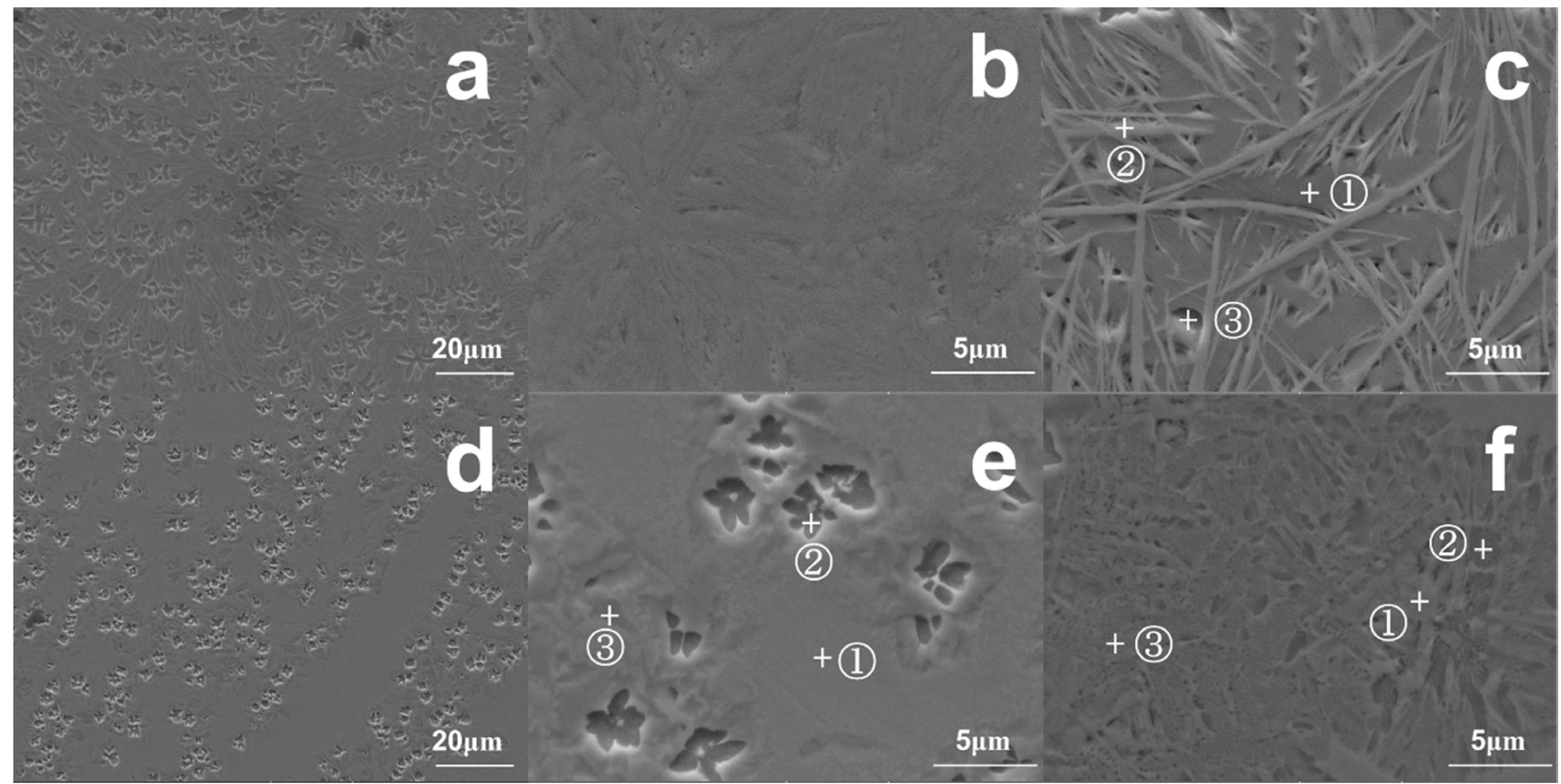

Fig. 5. Etched surfaces of S-casted HT alloy (a-c) and ZT alloy (d-f) in suction-on part as shown in Fig. 1c 
EDS analysis for phase chracteraztion of suction-casted Ti-based alloys are etched in Kroll's reagent $\left(100 \mathrm{ml} \mathrm{H}_{2} \mathrm{O}, 6 \mathrm{ml} \mathrm{HNO}_{3}\right.$, $3 \mathrm{ml} \mathrm{HF}$ ) at room temperature. Number symbols with phases are belong to c, e and f of Fig. 5, respectively

\begin{tabular}{|c|c|c|c|c|c|c|c|c|c|c|}
\hline \multirow{3}{*}{ Element } & \multicolumn{3}{|c|}{ c } & \multirow{3}{*}{ Element } & \multicolumn{3}{|c|}{ e } & \multicolumn{3}{|c|}{ f } \\
\hline & (1) & (2) & (3) & & (1) & (2) & (3) & (1) & (2) & (3) \\
\hline & \multicolumn{3}{|c|}{ at. \% } & & \multicolumn{6}{|c|}{ at. \% } \\
\hline$O K$ & 13.66 & 06.04 & 13.55 & $O K$ & 16.35 & 18.53 & 16.38 & 14.97 & 29.16 & 23.60 \\
\hline$T i K$ & 46.26 & 28.39 & 60.80 & $T i K$ & 34.64 & 45.58 & 42.48 & 46.15 & 32.66 & 28.53 \\
\hline$H f L$ & 07.23 & 09.82 & 02.10 & $Z r L$ & 09.89 & 07.21 & 06.88 & 07.37 & 02.97 & 04.93 \\
\hline$P d L$ & 10.84 & 20.90 & 01.78 & $P d L$ & 12.37 & 05.82 & 12.43 & 11.49 & 12.95 & 14.18 \\
\hline$C u K$ & 19.67 & 33.86 & 02.58 & $C u K$ & 21.99 & 10.40 & 18.64 & 16.24 & 17.66 & 25.30 \\
\hline$S n L$ & 02.35 & 01.00 & 19.19 & $S n L$ & 04.77 & 12.46 & 03.19 & 03.78 & 04.60 & 03.46 \\
\hline
\end{tabular}

Marble-like matrix with fine lamellar microstrutures on the surface of S-casted HT alloy was observed by etchant in Fig. 5a-c. There is two different phases which are grey phase and fine lamellar phase with under $1 \mu \mathrm{m}$ size as shown in Fig. 5c1 and c(2), respectively. Grey phase has a similar composition of mothe alloy, lower $\mathrm{Cu}$ contentration than its of mother alloy seems as though etchant dose after titanium oxide breakdown. Existence of $\mathrm{HfSn}_{2}$ and $\mathrm{TiPd}_{2}$ phases and elution of $\mathrm{Ti}_{2} \mathrm{Sn}$ and Ti-Cu binary phases are predicted in Table 1c(1) by Table 2 . Fine-densed lamellar phase has low contentration of Ti and $\mathrm{Sn}$ and Pd-rich. This phase is looked at as $\mathrm{Ti}_{3} \mathrm{Pd}$ phase and $\mathrm{Cu}-\mathrm{Ti}$ binary phases. $\mathrm{Cu}$-rich phases diffued in $\mathrm{Pd}$-rich phase matrix and elution of small amount of $\mathrm{HfSn}_{2}$ phase are consisted in Table 1c(2). High concent of O, Ti and $\mathrm{Sn}$ was dectected in breakdown region of Fig. $53 \mathrm{c}(3)$ in Table $2 \mathrm{c}(3)$ due to breakdown of Pd-rich layer and containig phase with the enclosed $\mathrm{Cu}$-rich phase as shown in Table 1c(3). High coolinng rate makes densed lamellar microstructure in suction-on part as shown in Fig. 1c.

Meanwhile, different phase matrix with fine etched microstrutures in S-casted ZT alloy as reference was observed by etchant in Fig. 5d-f. Especially, non-etched region was revealed by etchant. According to BFA of metallic glass in this composition, I-casted ZT metallic glass has a high BFA than I-casted HT metallic glasses [10]. This non-etched region seems to be high amorphization of ZT alloy although same cooling condition by suction casting. Dark phase and grey phase have difference of Ti concentration, variation of Ti-Cu binary phase and elution of $\mathrm{ZrCu}$ phase in table 1e(1) and 1e(3). The breakdown region in Fig. 5e(2) has titanium oxide rich layer and $\mathrm{Cu}$-rich-Zr binary phase- eluted trace by breakdown of Pd-riched phase layer in table 1e(2). Fig. 5f shows detail of initial surface texture on S-casted ZT alloy by wet chemical etching. Light greyish phase as shown in Fig. 5f(1) has a higher oxygen concentration which is comparable with those of other phases in Table $1 \mathrm{f}(1)$.

On the contrary, exposed underlay by breakdown of Pd-rich layer was able to trace structure of $\mathrm{Pd}$-rich layer which is consist of rich Pd-Ti, Sn-Ti and Cu-Ti binary phases in Table $1 \mathrm{f}(2)$. In case of the crystallized of S-casted ZT alloy with a high glass forming ability, $\mathrm{Ti}, \mathrm{Zr}$ and $\mathrm{Pd}$ that compose surface layer has enriched protection in wet corrosive environment with $\mathrm{NO}_{3}{ }^{-}, \mathrm{SO}_{4}{ }_{4}^{2-}$, $\mathrm{OH}^{-}$and $\mathrm{Cl}^{-}$radicals. In addition, densed mesh-like structure in Fig. $5 \mathrm{f}(3)$ was observed that low degree of crystallinity had higher protective potential than crystalline after grain coarsening. Fine crystallinity has a high potential to be contributed the inhibition of growth of corrosion cracking behaviour on the surface of these Ti-based alloys. HT alloy, however, has inhibition of corrosion by oxide layer with rich Ti- and Pd-phases on the surface in this study.

However, the $\mathrm{Ti}_{42} \mathrm{Hf}_{10} \mathrm{Pd}_{10} \mathrm{Cu}_{30} \mathrm{Sn}_{5} \mathrm{BMG}$ with improved mechanical properties also has good activation energy for crystallization in Fig. 6. The formation of stable glassy phase has closely related mechanical properties. Plotting of activation of crystallization by Kissinger equation [14] is effective method to characterize stability of glassy phase for crystallization [15].

$$
\operatorname{In}\left(\frac{\Phi}{T_{x}^{2}}\right)=-\frac{E a}{R T_{x}}+\text { constant }
$$

Where $\Phi$ is the applied heating rate, $T_{x}$ is the related temperature, $E_{a}$ is the activation energy of crystallization and $R$ is gas constant. The activation energy of the crystallization for the $\mathrm{Ti}_{42} \mathrm{Hf}_{10} \mathrm{Pd}-$ ${ }_{10} \mathrm{Cu}_{30} \mathrm{Sn}_{5} \mathrm{BMG}$ obtained crystallization temperature in calorimetric traces (as shown in Fig. 6a) by proposed heating rates. The obtained temperatures were plotted by Kissinger equation (as shown in Fig. 6b). Especially, $E_{x 1}$ and $E_{x 2}$ are higher values than those of the recently developed large plastic deformation type Ti-Zr-Ni-Cu-Be-Nb [16] and Ti-Cu-Zr-Ni-Sn system [17]. As a result, Ti-based BMG in this study has improved the mechanical properties and stability of glassy phase by substituting hafnium instead of zirconium.

\section{Conclusion}

In this study, we have successfully developed the $\mathrm{Ti}_{42} \mathrm{Hf}_{10}$ $\mathrm{Pd}_{10} \mathrm{Cu}_{30} \mathrm{Sn}_{5}$ BMG with the improved mechanical properties and observed thermal behaviour and fracture characteristics. It summarizes as following:

(1) The Ti-based BMG has compressive strength for $1990 \mathrm{MPa}$, elastic modulus for $94 \mathrm{GPa}$ and plastic deformation for $7 \%$ in longitudinal variation. 

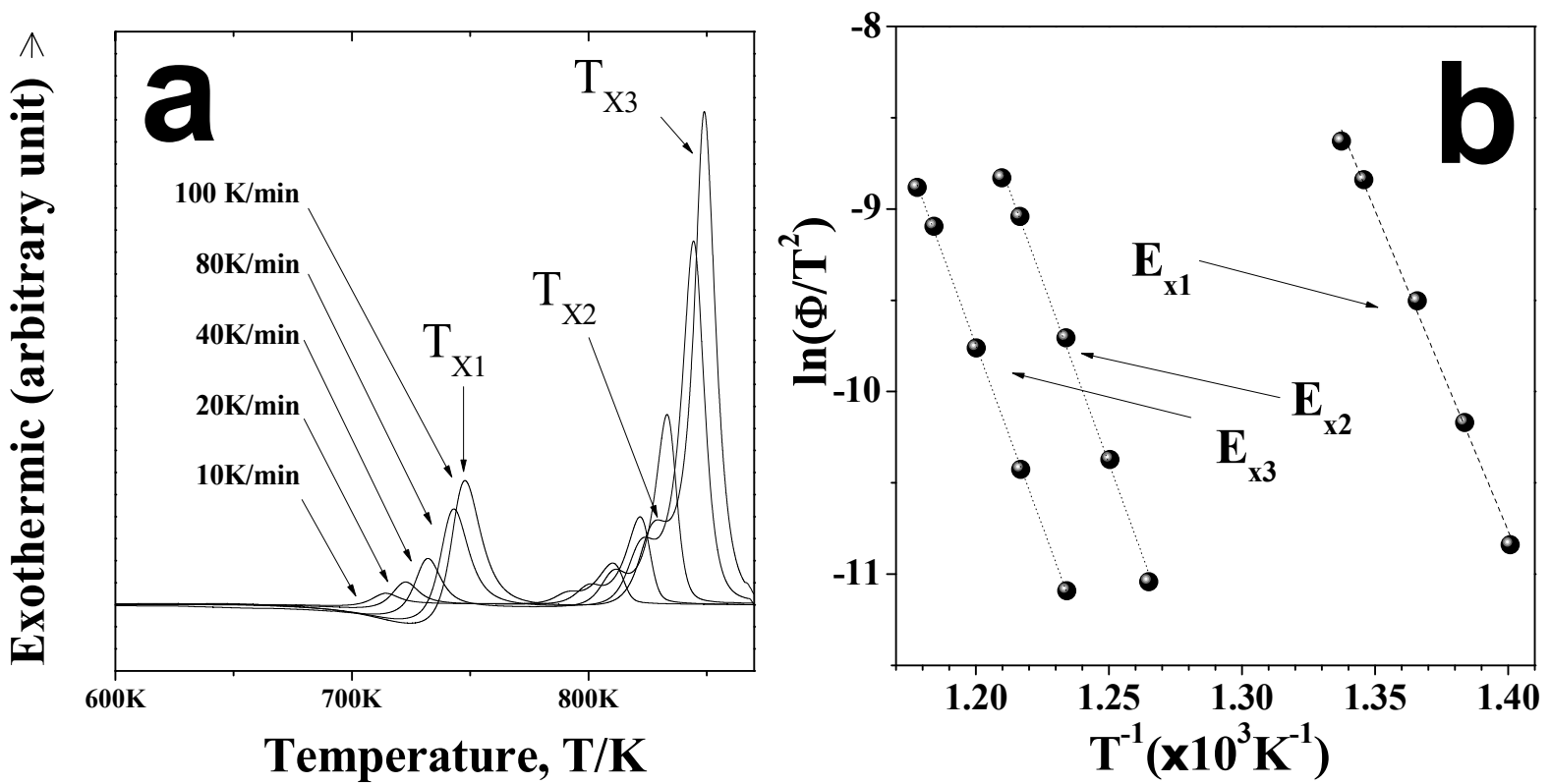

Fig. 6. Differential scanning calorimeter traces at the heating rate of $10 \mathrm{~K} / \mathrm{min}, 20 \mathrm{~K} / \mathrm{min}, 40 \mathrm{~K} / \mathrm{min}, 80 \mathrm{~K} / \mathrm{min}$ and $100 \mathrm{~K} / \mathrm{min}$ (a) and activation energy for crystallization by Kissinger equation (b) of HT-BMG

(2) The Ti-based glassy alloy has the reduced glass parameters as following $T_{x}, T_{r g}$ and $\gamma$ are $79 \mathrm{~K}, 0.50$ and 0.38 , respectively.

(3) Hafnium increases solid solubility limit in Ti-based BMG and it is one of considerable method of improving mechanical properties in Ti-based BMGs.

(4) The activation energies for crystallization of Ti- based BMG are estimated as $E_{x 1}=291.77 \pm 9.71 \mathrm{~kJ} / \mathrm{mol}, E_{x 2}=588.77$ $\pm 28.88 \mathrm{~kJ} / \mathrm{mol}$ and $E_{x 3}=330.26 \pm 3.61 \mathrm{~kJ} / \mathrm{mol}$ by Kissinger plotting.

\section{Acknowledgements}

This work was supported by BK21PLUS, Social Enterprise Specialist Development Group.

\section{REFERENCES}

[1] A. Inoue, Acta Mater. 48, 279-306 (2000).

[2] M.W. Chen, Npg Asia Materials 3, 82-90 (2011).

[3] J.J. Oak, A. Inoue, Mater. Scie. Eng. A 449, 220-224 (2007).

[4] J.J. Oak, A. Inoue, J. Non-Cryst. Solids 354, 1828-1832 (2008).
[5] J.J. Oak, D.V. Louzguine-Luzgin, A. Inoue, Appl. Phys. Lett. 91, 053106 (2007).

[6] J.J. Oak, D.V. Louzguine-Luzgin, A. Inoue, J. Mater. Res. 22, 1346-1353 (2007).

[7] J.J. Oak, D.V. Louzguine-Luzgin, A. Inoue, Mater. Scie. Eng. C, 29, 322-327 (2009).

[8] L. Bai, C.X. Cui, Q.Z. Wang, S.J. Bu, Y.M. Qi, J. Non-Cryst. Solids 354, 3935-3938 (2008).

[9] C.R. Barrett, W.D. Nix, A.S. Tetelman, The principles of engineering materials, Prentice-Hall, Englewood Cliffs, N.J., 1973.

[10] J.J. Oak, H. Kimura, A. Inoue, Advanced Materials Research 26-28, 785-788 (2007).

[11] R. Arroyave, T.W. Eagar, L. Kaufman, J. Alloy. Compd. 351, 158-170 (2003).

[12] U.E. Klotz, C.L. Liu, P.J. Uggowitzer, J.F. Loffler, Intermetallics 15, 1666-1671 (2007).

[13] P.G. Qin, H. Wang, L.G. Zhang, H.S. Liu, Z.P. Jin, Mater. Scie. Eng. A 476, 83-88 (2008).

[14] H.E. Kissinger, Anal. Chem. 29, 1702-1706 (1957).

[15] M.V. Susic, Mater. Chem. Phys. 12, 99-109 (1985).

[16] J.N. Mei, J.S. Li, H.C. Kou, J.L. Soubeyroux, H.Z. Fu, L. Zhou, J. Alloy. Compd. 467, 235-240 (2009).

[17] K.F. Xie, K.F. Yao, T.Y. Huang, Intermetallics 18, 1837-1841 (2010). 